\title{
Obtenção de extratos de guaraná ricos em cafeína por processo enzimático e adsorção de taninos
}

\author{
Production of caffeine-rich guarana extracts using
} an enzymatic process and tannin adsorption

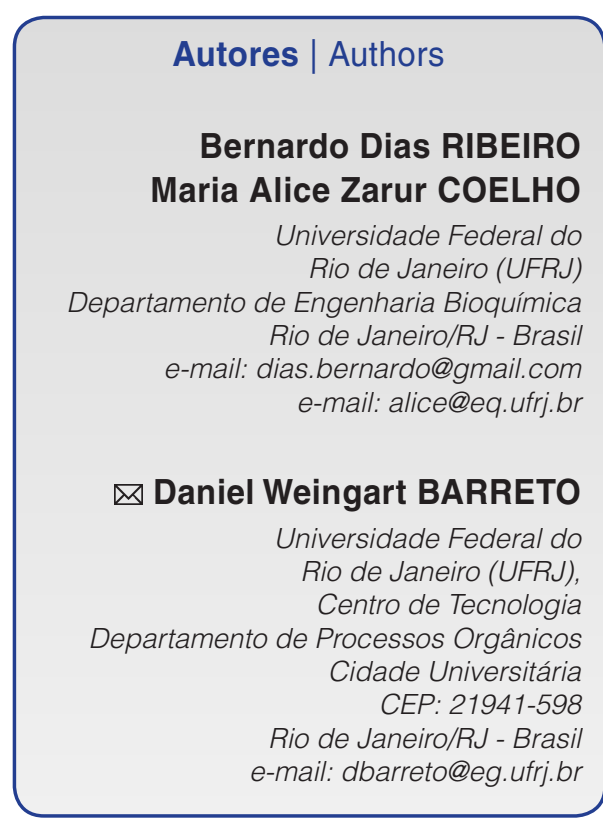

$\checkmark$ Autor Correspondente / Corresponding Author

Recebido / Received: 19/01/2010 Aprovado / Approved: 04/06/2012 Publicado / Published: set./2012

\section{Resumo}

As bebidas sabor guaraná são muito populares no Brasil e têm apresentado um excelente potencial de vendas no mercado externo. De acordo com as leis brasileiras, bebidas sabor guaraná devem conter entre $0,02 \mathrm{~g}$ a 0,2 g de semente de guaraná ou equivalente, para cada $100 \mathrm{~mL}$ de produto. Tais teores são usualmente obtidos pela adição de um extrato concentrado hidroalcoólico ou xarope de açúcar contendo extrato de guaraná diretamente à bebida. A utilização desses extratos em concentrações mais elevadas, entretanto, é limitada pela presença dos taninos, que conferem adstringência e coloração escura ao produto final. Neste trabalho, foi estudado o desenvolvimento de um processo enzimático para obtenção de extratos não alcoólicos de guaraná, de forma a produzir um extrato contendo baixas concentrações de taninos e teores elevados de cafeína, utilizando-se planejamento experimental e processos de adsorção. Por meio de um planejamento fatorial fracionário, foram determinadas as quantidades de $0,25 \%(\mathrm{v} / \mathrm{v})$ de pectinase e $0,1 \%(\mathrm{v} / \mathrm{v})$ de glucoamilase, sendo mantidas no planejamento composto central, que obteve como condições ótimas: $0,23 \%(\mathrm{v} / \mathrm{V})$ de celulase, $0,86 \%(\mathrm{v} / \mathrm{v})$ de hemicelulase e $1 \%(\mathrm{v} / \mathrm{v})$ de alfa-amilase durante $5,5 \mathrm{~h}$ de extração a $200 \mathrm{rpm}$ e $50{ }^{\circ} \mathrm{C}$, obtendo-se uma relação cafeína/tanino de 1,65. Com o processo de adsorção com óxido de magnésio a 10\% (p/v), foi alcançada uma relação de cafeína-tanino de 7,3.

Palavras-chave: Enzimas; Guaraná; Cafeína; Taninos.

\section{Summary}

Guarana-flavoured beverages are very popular in Brazil and have shown an excellent sales potential on foreign markets. According to Brazilian law, each $100 \mathrm{~mL}$ of guarana-flavoured beverages must contain between $0.02 \mathrm{~g}$ and $0.2 \mathrm{~g}$ of guarana seed or its equivalent. These levels are normally obtained by adding a concentrated hydroalcoholic extract or sugar syrup containing guarana extract, directly to the beverage. However, the use of more concentrated extracts is limited by the presence of tannins, which imparts astringency and a dark colour to the final product. In this work the development of an enzymatic process to obtain non-alcoholic guarana extracts with low tannin concentrations and high caffeine contents was studied using an experimental design and adsorption processes. By way of a fractional factorial design the quantities of $0.25 \%(\mathrm{v} / \mathrm{v})$ pectinase and $0.1 \%(\mathrm{v} / \mathrm{v})$ glucoamylase were determined, which were maintained in the central composite design, obtaining as the optimal conditions: $0.23 \%(\mathrm{v} / \mathrm{v})$ cellulase, $0.86 \%(\mathrm{v} / \mathrm{v})$ hemicellulase, $1 \%(\mathrm{v} / \mathrm{v})$ alpha-amylase, $5.5 \mathrm{~h}$ extraction time, $200 \mathrm{rpm}$ and $50{ }^{\circ} \mathrm{C}$, producing a caffeine/tannin ratio of 1.65 . Using a magnesium oxide adsorption process at $10 \%(\mathrm{w} / \mathrm{v})$, a caffeine/tannin ratio of 7.3 was obtained.

Key words: Enzymes; Guarana; Caffeine; Tannin. 


\section{Introdução}

Bebidas energéticas ou estimulantes são produtos alimentícios formulados como uma combinação de aminoácidos (taurina), purinas (cafeína), vitaminas do complexo B, açúcares (maltodextrina e glucoronolactona) e extratos vegetais, como guaraná e ginseng, que agem contra o desgaste físico e mental. Essas bebidas apresentam um consumo mundial de mais de um bilhão de litros, representando um mercado da ordem de 3,5 bilhões de dólares por ano. No Brasil, o mercado também apresenta um ritmo acelerado de crescimento, com mais de 21 milhões de litros comercializados, tendo movimentado valores próximos de 600 milhões de dólares em 2008 (BABU et al., 2008; ABIR, 2009).

O guaraná - Paullinia cupana Kunth ex H.B.K. var. sorbilis (Mart.) Ducke, família Sapindaceae - é uma trepadeira lenhosa originária da Amazônia Central, podendo atingir $10 \mathrm{~m}$ de altura, gerando cachos com até 50 frutos, cada qual com uma a três sementes. Estas são valorizadas por seu alto conteúdo de cafeína, que pode variar de 2,5 e 6\%, e ainda por seus efeitos estimulatórios quando consumidas como bebida; possui também propriedades adstringentes e antioxidantes, devidas à presença de taninos condensados ou proantocianidinas, que são polímeros de catequina e/ou epicatequinas (Figura 1b) (HENMAN, 1982; CARLSON e THOMPSON, 1998; SIMÕES et al., 2003). O conteúdo de cafeína do guaraná é significativamente maior (4 vezes) que o do café, 10 vezes maior do que o do chá, e 30 vezes maior do que o do cacau (EDWARDS et al., 2005). Além disso, as sementes de guaraná são constituídas por polissacarídeos, como amido, celulose, pectina, mucilagens, proteínas e óleo, além de teofilina, teobromina e saponinas (SIMÕES et al., 2003; HEARD et al., 2006).
A produção brasileira anual de sementes de guaraná é de cerca de 3 mil toneladas, sendo que a maior parte (70 a $80 \%$ ) é usada na preparação de refrigerantes e bebidas energéticas. Parte (15\%) das sementes também é industrializada na forma de bastão e o restante é utilizado na produção de pós, extratos e xaropes, vendidos diretamente no mercado brasileiro (MAGNA et al., 2003; SIMÕES et al., 2003; EDWARDS et al., 2005; PAGLIARUSSI et al., 2006). Nos Estados Unidos, o guaraná foi aprovado como suplemento alimentar e também é utilizado como aromatizante natural de bebidas (CARLSON e THOMPSON, 1998; HULBERT et al., 1998).

De acordo com o Parágrafo 10 do Artigo 13 do Anexo da Lei no 8918 de 14/07/1994 da Legislação Brasileira (BRASIL, 2009), qualquer bebida não alcoólica que contiver semente de guaraná deverá apresentar os teores dos componentes secundários do guaraná, sendo proibida a adição de cafeína sintética ou obtida de outro vegetal. No Parágrafo 11, nesse mesmo artigo dessa lei, é relatado que, nesse tipo de bebida, o limite de cafeína não poderá ser superior a $20 \mathrm{mg} .100 \mathrm{~mL}^{-1}$ do produto a ser consumido. Assim, para se obter uma bebida energética com maior quantidade desse ingrediente, é necessário produzir um extrato de guaraná mais concentrado em cafeína.

O método tradicional e mais utilizado para a produção de extratos de guaraná é baseado na extração direta das sementes com uma solução hidroalcoólica. A produção de um extrato de guaraná envolvendo uma etapa de hidrólise enzimática foi recentemente apresentada pela empresa Mie Kariyou Corp (2000), alcançando 5\% de cafeína e $13,4 \%$ de taninos, em relação ao extrato seco de guaraná. O extrato obtido por meio dos processos convencionais, entretanto, se apresenta na forma de uma<smiles>CCn1cnc2c(c1=O)c(=O)n(C)c(=O)n2C</smiles>

Figura 1. Estruturas moleculares de (a) cafeína e (b) proantocianidina. 
solução de cor castanho escuro, sendo bastante rico em cafeína e em taninos. Isso ocorre em função da formação de um complexo entre a cafeína e os taninos, formado por meio de interações hidrofóbicas e de uma ligação de hidrogênio entre o átomo de nitrogênio não metilado no anel imidazol da cafeína e o grupo hidroxila dos taninos (SPENCER et al., 1988; EDWARDS et al., 2005). Assim, a utilização desses extratos de guaraná em concentrações mais elevadas é limitada, em função da presença de altas concentrações de taninos, os quais são indesejáveis pelo seu amargor e pela sua adstringência (HENMAN, 1982).

Para desfazer o complexo cafeína-taninos, algumas estratégias podem ser realizadas, como a utilização de solventes seletivos para a extração de cafeína como fluido supercrítico ou cloreto de metileno (MEHR et al., 1996; HULBERT et al., 1998; SALDAÑA et al., 2002), ou então a troca da cafeína por outro componente no complexo, pelo qual os taninos condensados teriam maior afinidade, como proteínas (SPENCER et al., 1988; KAWAMOTO et al., 1996), íons metálicos (SIMÕES et al., 2003) e polímeros (MAKKAR et al., 1995).

No presente trabalho, foi estudada a produção de extratos de guaraná por processamento enzimático das sementes, com o auxílio de ferramentas estatísticas para análise e planejamento de experimentos, de forma a buscar a melhor alternativa de processo com o menor número de etapas experimentais possível. Também foram estudados diferentes métodos para a remoção parcial ou total dos taninos, baseando-se em sua característica de complexação com proteínas, íons metálicos e polímeros, de forma a obter extratos com teores de cafeína mais elevados em relação ao tanino.

\section{Material e métodos}

\subsection{Materiais}

As amostras de guaraná, em forma de pó, foram obtidas no mercado atacadista. Para análise de cafeína e taninos, foi utilizado um espectrofotômetro UV Hach modelo DR/4000 (Loveland, USA). As carboidrases utilizadas foram obtidas da empresa Novozymes (Araucária-PR, Brasil), sendo:

- Viscozyme: 100 FBG.g-1, densidade de $1,2 \mathrm{~g} \cdot \mathrm{mL}^{-1}$, em que $\mathrm{FBG}=$ Fungal BetaGlucanase Units, quantidade de enzima que hidrolisa beta-glucana a açúcares redutores, correspondendo a $1 \mu \mathrm{mol}$ de glicose por minuto em pH 5.0, a $30{ }^{\circ} \mathrm{C}$ durante $30 \mathrm{~min}$.

- AMG: $300 \mathrm{AGU} \cdot \mathrm{mL}^{-1}$, densidade de 1,2 g. $\mathrm{mL}^{-1}$, em que $A G U=$ Novo Amyloglucosidase Unit, quantidade de enzima que hidrolisa $1 \mu \mathrm{mol}$ de maltose por minuto em $\mathrm{pH} 5.0$, a $37^{\circ} \mathrm{C}$ durante 30 min.
- Ultrazym: $3400 \mathrm{FDU} 20^{\circ} \mathrm{C} \cdot \mathrm{mL}^{-1}$, densidade de $1,2 \mathrm{~g} \cdot \mathrm{mL}^{-1}$, em que FDU = Ferment Depectinzation Units, quantidade de enzima que despolimeriza 33,3 $\mathrm{mL}$ de suco padrão contendo $0,4 \mathrm{~g} \cdot \mathrm{L}^{-1}$ de pectina em $\mathrm{pH} 3,5$, a $55^{\circ} \mathrm{C}$ em $2 \mathrm{~h}$.

- Termamyl: $120 \mathrm{KNU} \cdot \mathrm{g}^{-1}$, densidade de 1,2 g. $\mathrm{mL}^{-1}$, em que KNU = Kilo Novo alpha-amylase Unit, quantidade de enzima que hidrolisa $5,26 \mathrm{~g}$ de amido por hora em $\mathrm{pH} 5,6$, a $37^{\circ} \mathrm{C}$, na presença de 0,0043 M de cálcio, durante 20 min.

- Cellubrix: 1500 NCU. $\mathrm{mL}^{-1}$, densidade de 1,2 g. $\mathrm{mL}^{-1}$, em que NCU = Novo Cellulase Unit, quantidade de enzima que hidrolisa CMC a açúcares redutores correspondendo a $1 \mu \mathrm{mol}$ de glicose por minuto em $\mathrm{pH} 4,8$, a $40{ }^{\circ} \mathrm{C}$ durante 20 min.

\subsection{Métodos analíticos}

As metodologias utilizadas para determinação dos açúcares redutores totais, da cafeína e dos taninos (compostos fenólicos totais) foram Somogyi (1952), Andrade et al. (1999) e de Folin-Denis (WATERMAN e MOLE, 1994), sendo que todas estas se baseiam em espectrofotometria. O teor de sólidos totais foi determinado por gravimetria de acordo com o método da Association of Official Analytical Chemists (HORWITZ, 1996).

\subsection{Procedimento experimental}

Primeiramente, para o delineamento dos grupos de enzimas com atuação relevante no processamento das sementes de guaraná, foi feito um planejamento fatorial fracionário do tipo $2^{5-1}$, utilizando-se o software Statistica 6.0 (StatSoft, Tulsa, USA). Como variáveis dependentes (fatores), foram consideradas diferentes concentrações de enzimas (celulase, hemicelulase, pectinase, amiloglicosidase e alfa-amilase), cujos níveis avaliados foram de 0, 0,5 e 1\%(v/v), isto é, volume do preparado enzimático comercial sem diluição pelo volume total de água utilizada na extração. Para melhor visualização dos efeitos dos fatores e suas interações sobre os resultados, foi utilizado o diagrama de Pareto, que apresenta os efeitos padronizados (valores absolutos calculados por meio da distribuição $t$ de Student) de cada parâmetro, sendo estes considerados relevantes se forem estatisticamente significativos; ou seja, quando o efeito padronizado do parâmetro for inferior ao $p$-valor (probabilidade de significância) de 0,05, para 95\% de confiança (RODRIGUES e IEMMA, 2005).

Durante os experimentos, foi mantida a proporção guaraná/água em 1/5 (p/v) em agitação constante de 200 rpm. As variáveis de resposta avaliadas foram os 
teores de sólidos totais (\%), açúcares redutores, cafeína e taninos $\left(\mathrm{g} \cdot \mathrm{L}^{-1}\right)$. Antes da adição das enzimas, o pó de sementes de guaraná foi mantido por 30 min para hidratação. Após esse período, foram adicionados sequencialmente preparados enzimáticos comerciais à base de celulases e hemicelulases, sendo que, em alguns testes, também foi realizada a adição de pectinases. Transcorrida a incubação com essas enzimas, foi adicionada ao meio reacional a enzima amiloglicosidase e, por fim, a enzima alfa-amilase. O extrato foi, então, aquecido a $100{ }^{\circ} \mathrm{C}$ por $5 \mathrm{~min}$, para a inativação das enzimas, com posterior separação por centrifugação a 1000 x g. A Figura 2 ilustra a sequência de adição das enzimas, com seus respectivos tempos de incubação.

Em uma segunda etapa, foi realizado outro conjunto de experimentos; dessa vez, um planejamento composto central, de forma a buscar condições experimentais ótimas que maximizassem o teor de cafeína em relação ao teor de tanino nos extratos, utilizando-se menores concentrações das enzimas. Os fatores consistiram nas concentrações das enzimas celulase, hemicelulase e alfaamilase, com níveis (teores) dos preparados de 0; 0,2; 0,$5 ; 0,8$ e 1\% (v/v). As demais condições experimentais foram mantidas fixas.

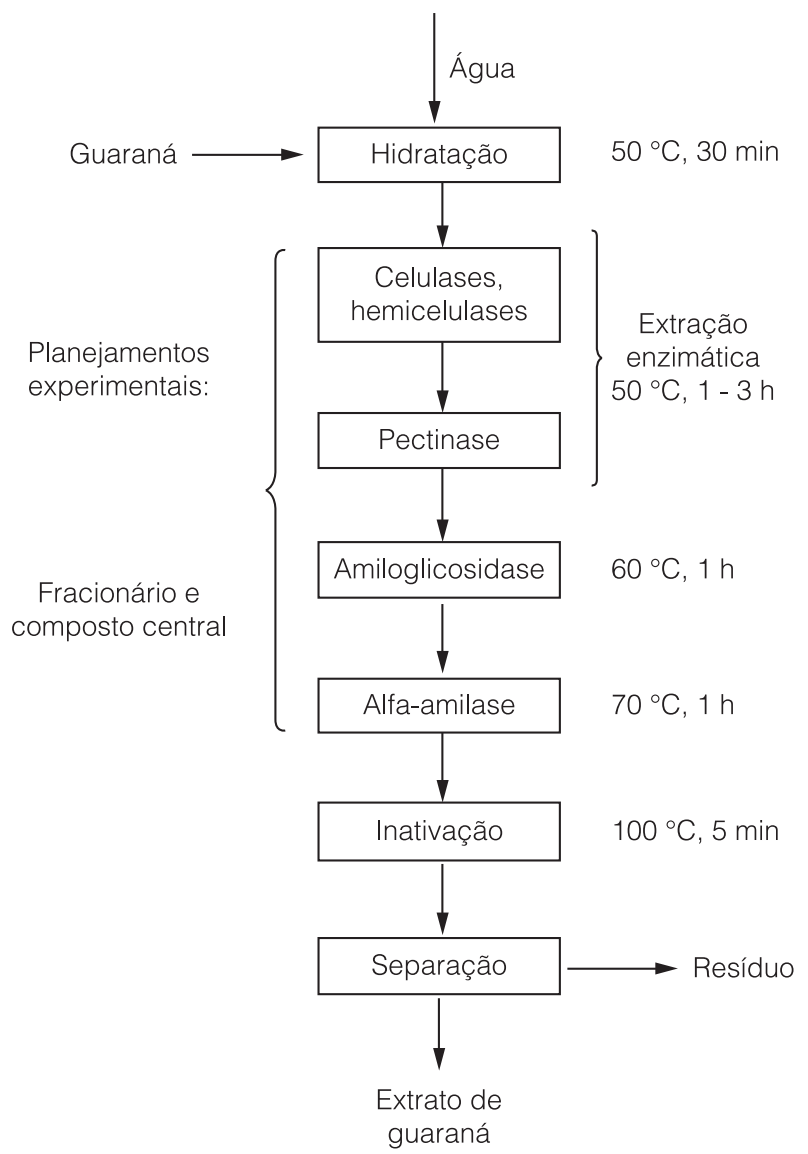

Figura 2 . Fluxograma do processo enzimático para obtenção de extrato de guaraná.
A ferramenta estatística utilizada pelo programa Statistica para otimizar várias variáveis de resposta - nesse caso, maximizar a cafeína, os açúcares redutores e os sólidos totais, e minimizar os taninos, visando elevar a relação cafeína/tanino - é a função desirability. Esta consiste em converter primeiro cada resposta $y_{i}$ em uma função individual desirability $\mathrm{d}_{\mathrm{i}}$, que varia de 0 a 1 . Nessa função, quanto mais próximo de 1, melhor o ajuste. Assim, as variáveis independentes são escolhidas de modo a maximizar a desirability global, definida como a média geométrica de todas as funções individuais $d_{i}$. As superfícies de resposta apresentam o comportamento da desirability global perante a variação de dois parâmetros, mas neste trabalho optou-se pelas curvas de nível para uma melhor visualização da região de maior desirability (CALADO e MONTGOMERY, 2003).

O extrato de guaraná preparado segundo as condições experimentais ótimas, determinadas pelo planejamento composto central, foi submetido a testes adicionais de adsorção seletiva de taninos, visando-se aumentar ainda mais a relação cafeína/tanino obtida. Para tanto, foi feita uma comparação da adição de $5 \%(\mathrm{p} / \mathrm{v})$ de alguns compostos, como Perlita e Celite (auxiliares de filtração), gelatina (proteína rica em prolina), PVPP (polivinilpirrolidona insolúvel), alumina e óxido de magnésio (adsorventes com íons metálicos). O sistema foi mantido a $50{ }^{\circ} \mathrm{C}$ por $1 \mathrm{~h}$ e sob agitação de 200 rpm em todos os casos testados. Como o PVPP e o óxido de magnésio proporcionaram os melhores resultados, estes foram testados novamente com concentrações diferentes, variando de 1 a $15 \%(p / v)$

\section{Resultados e discussão}

\subsection{Planejamento fatorial fracionário}

O planejamento fatorial fracionário geralmente é utilizado em delineamentos de fatores e de seus níveis, focando apenas nos efeitos principais e nas interações de primeira ordem (RODRIGUES e IEMMA, 2005). Por meio desse planejamento, foram obtidos os coeficientes de determinação $\left(R^{2}\right)$, que representam o grau de ajuste dos dados experimentais (Tabela 1) com os dados calculados, sendo estes de 0,872, 0,954 e 0,983 para as variáveis 'relação cafeína/tanino', 'teor de açúcares redutores totais' e 'teor de sólidos totais', respectivamente. Por meio do diagrama de Pareto (Figura 3), foi observado efeito antagônico da concentração de glucoamilase em relação à razão cafeína/tanino, embora essa variável tenha influenciado positivamente a hidrólise da matériaprima, evidenciada pelo aumento do teor de sólidos totais e açúcares redutores. Wu et al. (2009) relataram que os grupos hidroxilas dos polifenóis do chá (Camellia sinensis) interagiam com as cadeias laterais da amilopectina, se ligando às regiões amorfas do grânulo de amido. Isso 
Obtenção de extratos de guaraná ricos em cafeína por processo enzimático e adsorção de taninos

RIBEIRO, B. D. et al.

significa que, ao se hidrolisar o amido presente na semente do guaraná com a enzima glucoamilase, os taninos perdem a interação com o amido, tendo a sua liberação no extrato favorecida.
Alguns parâmetros também foram estatisticamente significativos na relação cafeína/tanino, atuando positivamente, como a celulase e as interações entre pectinase e glucoamilase, celulase e hemicelulase, e

Tabela 1. Resultados do processo enzimático do guaraná através de planejamento fatorial fracionário 25-1.

\begin{tabular}{ccccccccc} 
Ensaios & $\mathbf{C}$ & $\mathbf{H}$ & $\mathbf{P}$ & $\mathbf{G}$ & $\mathbf{A}$ & $\begin{array}{c}\text { Tólidos Totais } \\
(\%)\end{array}$ & $\begin{array}{c}\text { Respostas } \\
\text { Açúcares Redutores } \\
\left(\mathbf{g} \cdot \mathbf{L}^{-1}\right)\end{array}$ & $\begin{array}{c}\text { Relação } \\
\text { Cafeína/ Tanino }\end{array}$ \\
\hline 1 & 0 & 0 & 0 & 0 & 1 & 2,48 & 3,04 & 1,10 \\
2 & 1 & 0 & 0 & 0 & 0 & 3,26 & 3,46 & 1,15 \\
3 & 0 & 1 & 0 & 0 & 0 & 3,74 & 3,28 & 1,09 \\
4 & 1 & 1 & 0 & 0 & 1 & 4,93 & 3,32 & 1,45 \\
5 & 0 & 0 & 1 & 0 & 0 & 1,90 & 3,03 & 0,97 \\
6 & 1 & 0 & 1 & 0 & 1 & 3,87 & 3,06 & 0,91 \\
7 & 0 & 1 & 1 & 0 & 1 & 4,89 & 3,31 & 1,03 \\
8 & 1 & 1 & 1 & 0 & 0 & 5,31 & 3,46 & 0,94 \\
9 & 0 & 0 & 0 & 1 & 0 & 5,09 & 3,46 & 0,82 \\
10 & 1 & 0 & 0 & 1 & 1 & 5,77 & 3,54 & 0,90 \\
11 & 0 & 1 & 0 & 1 & 1 & 6,217 & 3,40 & 0,82 \\
12 & 1 & 1 & 0 & 1 & 0 & 5,93 & 3,31 & 0,83 \\
13 & 0 & 0 & 1 & 1 & 1 & 5,74 & 3,34 & 0,86 \\
14 & 1 & 0 & 1 & 1 & 0 & 6,04 & 3,44 & 0,91 \\
15 & 0 & 1 & 1 & 1 & 0 & 7,28 & 3,40 & 0,87 \\
16 & 1 & 1 & 1 & 1 & 1 & 9,74 & 3,46 & 0,78 \\
17 & 0,5 & 0,5 & 0,5 & 0,5 & 0,5 & 5,61 & 3,41 & 0,82 \\
18 & 0,5 & 0,5 & 0,5 & 0,5 & 0,5 & 5,59 & 3,45 & 0,76 \\
\hline 19 & 0,5 & 0,5 & 0,5 & 0,5 & 0,5 & 5,84 & 3,36 & \\
\hline
\end{tabular}

C: celulase; H: hemicelulase; P: pectinase; G: glucoamilase; A: alfa-amilase.

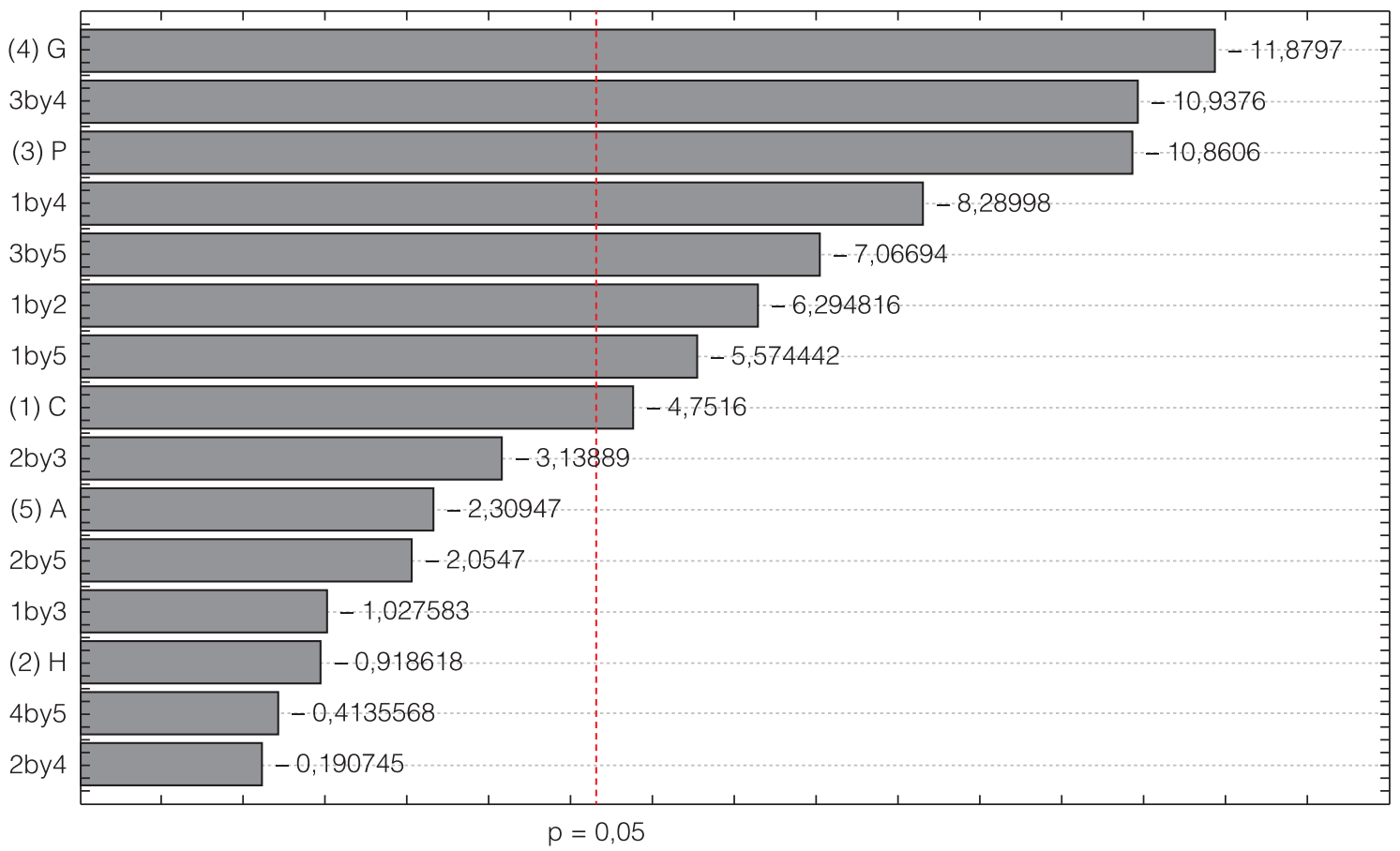

Figura 3. Diagrama de Pareto para relação cafeína/tanino do planejamento fatorial fracionário. 
celulase e alfa-amilase. Outros atuaram negativamente, como glucoamilase e pectinase, as interações celulase e glucoamilase, e pectinase e alfa-amilase. Visando ao aumento da relação cafeína/tanino, foi determinado pelo Statistica que as melhores condições de operação são conseguidas com $1 \%$ (v/v) da mistura de celulase, hemicelulase e alfa-amilase, 0,25\% (v/v) de pectinase e $0,1 \%(v / v)$ de glucoamilase.

Na medida em que o planejamento fracionário foi utilizado apenas para indicar e delimitar as faixas de valores dos parâmetros, posteriormente um planejamento experimental composto central em três níveis foi realizado, variando a quantidade de celulase, hemicelulase e alfa-amilase, e fixando a quantidade de pectinase e de glucoamilase, citada anteriormente.

\subsection{Planejamento composto central}

O planejamento composto central foi utilizado para otimização dos resultados, sendo, nesse caso, maximizar a relação cafeína/tanino e permitir encontrar a quantidade mínima de enzimas para que o processo tenha custo baixo. Por meio desse planejamento, foram obtidos os coeficientes de determinação $\left(R^{2}\right)$ de 0,643, 0,733 e 0,749 para as variáveis 'relação cafeína/tanino', 'teor de açúcares redutores totais' e 'teor de sólidos totais', respectivamente. Os termos quadráticos relacionados à quantidade de celulase e de hemicelulase, e o termo linear relacionado à quantidade de alfa-amilase foram os que apresentaram maior influência positiva sobre a relação cafeína/tanino, sendo que a interação entre celulase e hemicelulase apresentou o maior efeito negativo. Hanlin et al. (2010) relataram que os taninos também interagem com outros polissacarídeos da parede celular vegetal por meio de ligações de hidrogênio e de interações hidrofóbicas; estas são influenciadas pelos aspectos de estrutura, forma, massa molar e quantidade de polissacarídeos e taninos, sendo a interação maior com pectina, xiloglucana e celulose, em ordem decrescente. Na medida em que a interação entre celulase e hemicelulase tem efeito negativo, a utilização destas em concentrações inversas é necessária: nesse caso, uma quantidade maior de hemicelulase e menor de celulase. Isso proporciona uma matriz de semente de guaraná ainda com microfibrilas de celulose e grânulos de amido parcialmente hidrolisados que retém os taninos, impedindo parcialmente de estes se difundirem para o extrato.

A partir dos dados experimentais (Tabela 2), foram obtidas por meio da desirability as condições ótimas, sendo as quantidades de: $0,23 \%$ de celulase, $0,86 \%$ de hemicelulase e 1\% de alfa-amilase (Figura 4). Nessas condições, as concentrações de cafeína e taninos obtidas são de 4,45 e 2,70 (g.L $\left.\mathrm{L}^{-1}\right)$, respectivamente, gerando uma relação cafeína/tanino nesse extrato enzimático de guaraná duas vezes maior do que a relação observada no extrato sem enzimas, no valor de 0,83 , com concentrações de cafeína e taninos de 3,92 e 4,72 (g. $\left.\mathrm{L}^{-1}\right)$, respectivamente. Na medida em que a enzima glucoamilase foi mantida em uma concentração fixa nesse planejamento $(0,1 \%$ p/v) e esta era a que mais influenciava nos teores de sólidos totais e açúcares redutores totais, essas variáveis de resposta proporcionaram resultados nos ensaios do planejamento composto central relativamente próximos.

Tabela 2. Resultados do processo enzimático do guaraná através de planejamento composto central.

\begin{tabular}{ccccccc} 
Ensaios & $\mathbf{C}$ & $\mathbf{H}$ & $\mathbf{A}$ & $\begin{array}{c}\text { Solidos Totais } \\
\mathbf{( \% )}\end{array}$ & $\begin{array}{c}\text { Açúcares Redutores } \\
\left(\mathbf{g} \cdot \mathbf{L}^{-1} \mathbf{)}\right.\end{array}$ & $\begin{array}{c}\text { Relação Cafeína/ } \\
\text { Tanino }\end{array}$ \\
\hline 1 & 0,2 & 0,2 & 0,2 & 3,55 & 5,88 & 1,36 \\
2 & 0,2 & 0,2 & 0,8 & 3,74 & 6,03 & 1,31 \\
3 & 0,2 & 0,8 & 0,2 & 4,15 & 6,43 & 1,45 \\
4 & 0,2 & 0,8 & 0,8 & 4,42 & 6,39 & 1,65 \\
5 & 0,8 & 0,2 & 0,2 & 3,57 & 6,31 & 1,42 \\
6 & 0,8 & 0,2 & 0,8 & 4,07 & 6,09 & 1,48 \\
7 & 0,8 & 0,8 & 0,2 & 4,35 & 6,49 & 1,42 \\
8 & 0,8 & 0,8 & 0,8 & 4,48 & 6,17 & 1,52 \\
9 & 0 & 0,5 & 0,5 & 3,91 & 6,50 & 1,31 \\
10 & 1 & 0,5 & 0,5 & 4,39 & 6,34 & 1,41 \\
11 & 0,5 & 0 & 0,5 & 4,21 & 6,25 & 1,36 \\
12 & 0,5 & 1 & 0,5 & 4,81 & 6,75 & 1,27 \\
13 & 0,5 & 0,5 & 0 & 4,28 & 6,90 & 1,13 \\
14 & 0,5 & 0,5 & 1 & 4,65 & 7,07 & 1,20 \\
15 & 0,5 & 0,5 & 0,5 & 3,81 & 6,92 & 1,20 \\
16 & 0,5 & 0,5 & 0,5 & 3,90 & 6,91 & 1,22 \\
\end{tabular}

C: celulase; $\mathrm{H}$ : hemicelulase; A: alfa-amilase. 
Obtenção de extratos de guaraná ricos em cafeína por processo enzimático e adsorção de taninos

RIBEIRO, B. D. et al.
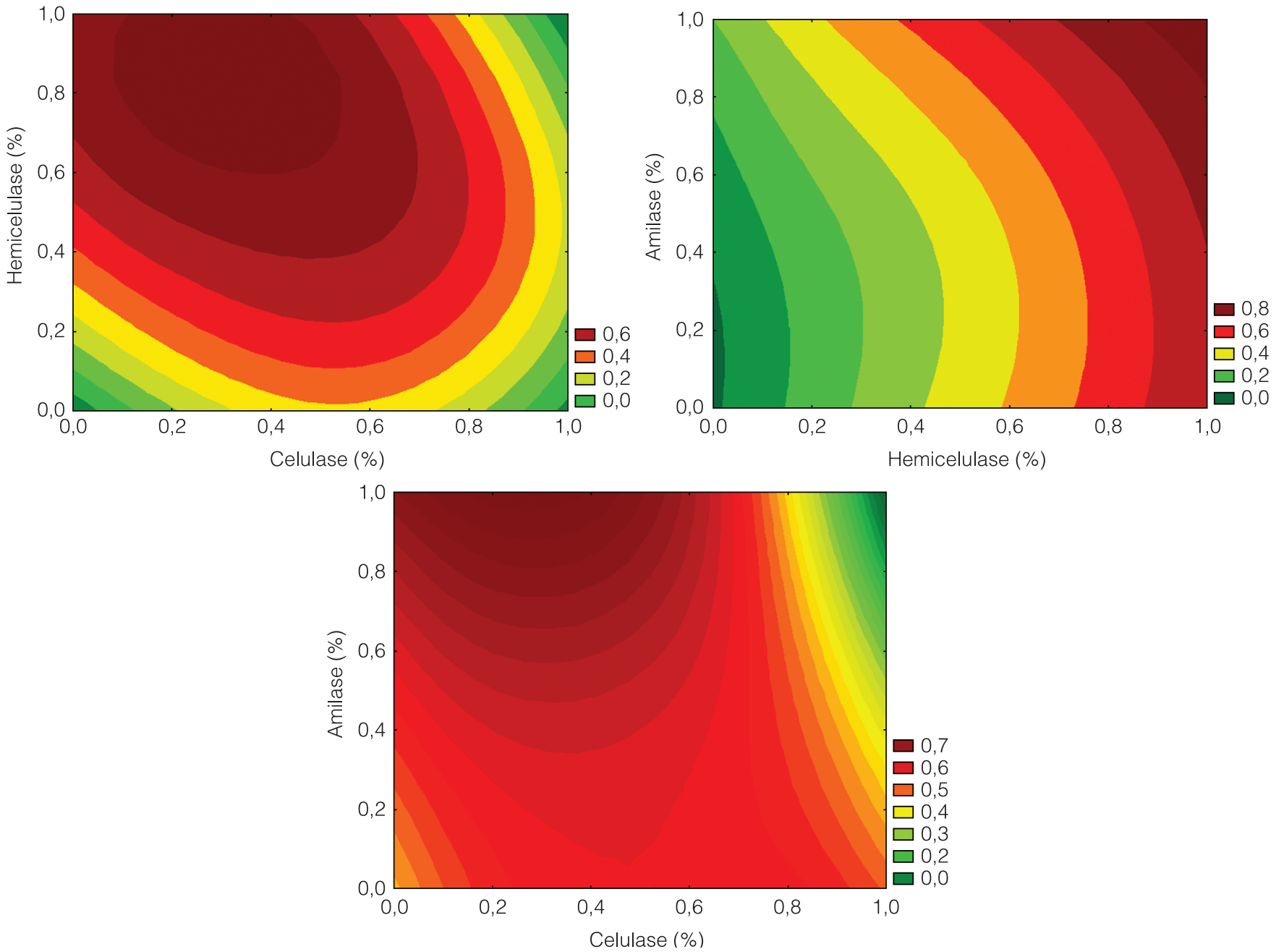

Figura 4. Curvas de contorno da otimização do processamento enzimático de sementes de guaraná.

\subsection{Pós-processamento}

Os taninos condensados podem interagir com várias moléculas além de polissacarídeos, como os íons $\mathrm{Fe}^{3+}$, $\mathrm{Cu}^{2+}, \mathrm{Zn}^{2+}, \mathrm{Pb}^{2+}, \mathrm{Mg}^{2+} \mathrm{Al}^{3+}$, proteínas - principalmente as que possuem maior quantidade do aminoácido prolina - e a cafeína (SPENCER et al., 1988; SANTOS-BUELGA e SCALBERT, 2000; ESPARZA et al., 2005). Explorando-se essas interações com íons metálicos, algumas argilas já foram utilizadas para remoção dos taninos de efluentes industriais, como bentonita $\left(\mathrm{SiO}_{2}-\mathrm{Al}_{2} \mathrm{O}_{3}\right)$ (ANIRUDHAN e RAMACHANDRAN, 2006), atapulgita (silicatos de magnésio hidratados) (HUANG et al., 2008) e hidrotalcita $\left(\mathrm{Mg}_{6} \mathrm{Al}_{2}(\mathrm{OH})_{16}\left(\mathrm{CO}_{3}\right)\right)$ (ANIRUDHAN e SUCHITHRA, 2007).

$\mathrm{Na}$ medida em que o objetivo é a produção de extratos de guaraná ricos em cafeína, após o processamento enzimático foram testados alguns tratamentos para a adsorção e a remoção seletiva dos taninos presentes no extrato de guaraná, explorando as interações dos taninos com íons $\mathrm{Mg}^{2+} \mathrm{e} \mathrm{Al}^{3+}$ (alumina e oxido de magnésio), com proteína rica em prolina (gelatina) ou similar (PVPP), já que a estrutura do anel pirrolidínico polimérico é próximo da prolina, além de auxiliares de filtração comerciais (Perlita e Celite), que poderiam interferir no complexo entre cafeína e tanino. Conforme observado na Figura 5, apenas o óxido de magnésio e o PVPP apresentaram um desempenho satisfatório, 80 e 190\% superiores, respectivamente, à relação cafeína-tanino encontrada no extrato enzimático sem pós-tratamento. A adsorção dos taninos pelo PVPP ocorre pela formação de ligação de hidrogênio entre os grupos hidroxilas das catequinas com o grupo carbonila do PVPP, junto com as interações hidrofóbicas entre os anéis aromáticos dos polifenóis e 0 anel pirrolidínico do PVPP (MAGALHÃES et al., 2010). Diversamente, a adsorção pelo óxido de magnésio é devida à formação de complexo metal-tanino, o qual pode ser estabilizado pela nuvem eletrônica dos anéis aromáticos da catequina que envolve o ín (ESPARZA et al., 2005), sendo que ambos parecem ter mais afinidade pelos taninos do que a cafeína, pelos resultados encontrados.

Para otimizar o aumento da relação cafeínatanino no extrato de guaraná, foram testadas diferentes 
Obtenção de extratos de guaraná ricos em cafeína por processo enzimático e adsorção de taninos RIBEIRO, B. D. et al.

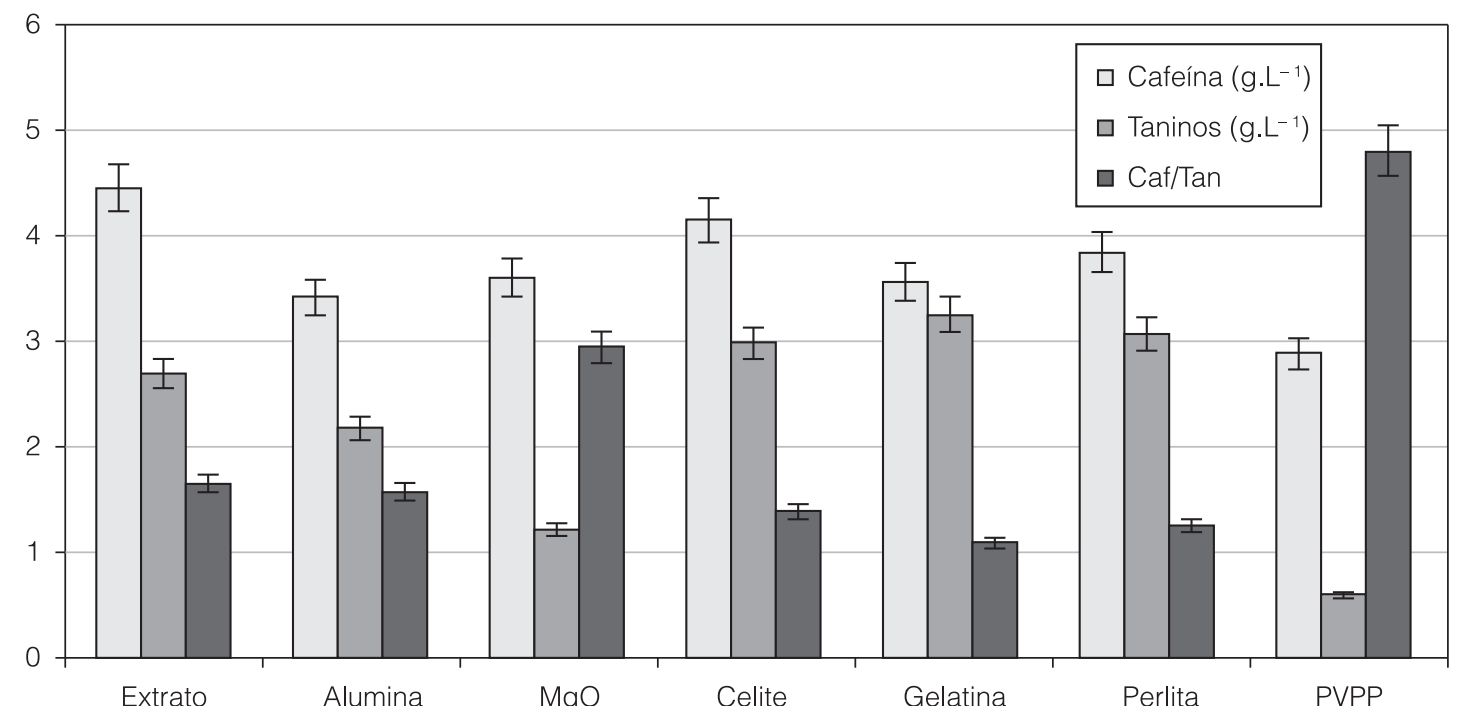

Figura 5. Pós-processamento do extrato de guaraná utilizando diferentes sistemas de adsorção.

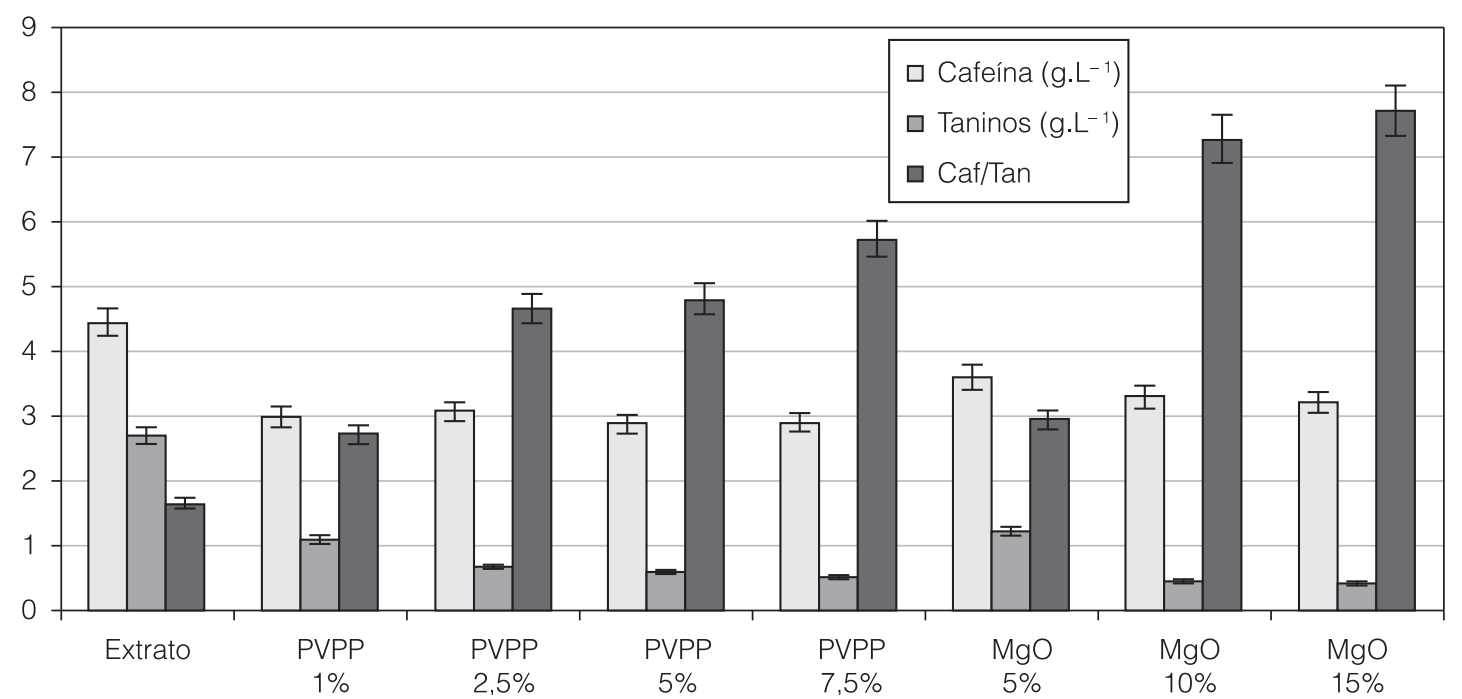

Figura 6. Otimização do pós-processamento do extrato de guaraná utilizando polivinilpirrolidona (PVPP) e óxido de magnésio em diferentes concentrações.

concentrações dos dois adsorventes (óxido de magnésio e PVPP) que apresentaram o melhor desempenho nos ensaios preliminares. A adição de óxido de magnésio a 10\% (p/v) apresentou o melhor resultado da série, alcançando uma relação de cafeína-tanino de 7,3 (Figura 6), com concentrações de cafeína e de taninos de 3,30 e 0,45 g. $\mathrm{L}^{-1}$, respectivamente. 0 PVPP em 7,5\% (p/v) também proporcionou um bom resultado com uma proporção cafeína-tanino de 5,7 (concentrações de cafeína e taninos iguais a 2,91 e 0,51 g. $\mathrm{L}^{-1}$, respectivamente); entretanto, além de o PVPP ser inferior a óxido de magnésio, tem um custo superior.

\section{Conclusões}

O processamento enzimático para produção de extrato de guaraná, seguido do pós-processamento do extrato com óxido de magnésio, representa uma alternativa interessante para a indústria alimentícia, pois permite a extração seletiva de cafeína e taninos das sementes de guaraná sem o emprego de condições severas de operação e sem o uso de solventes orgânicos inflamáveis, tóxicos e perigosos.

A adição de óxido de magnésio a 10\% (p/v) ao extrato de guaraná permitiu a remoção seletiva dos taninos, levando o produto a uma relação cafeína-tanino de 7,3, sendo esta dez vezes superior à observada no extrato inicial. Portanto, a metodologia proposta permitiu a obtenção de um extrato com elevada concentração de cafeína e teores reduzidos de taninos, resultando em um ingrediente de menor adstringência e, provavelmente, com excelente aplicação como aditivo no mercado de alimentos funcionais. 
Obtenção de extratos de guaraná ricos em cafeína por processo enzimático e adsorção de taninos RIBEIRO, B. D. et al.

\section{Referências}

ANDRADE, L.; SCHENKEL, E. P.; BERGOLD, A. M. Estudo da metodologia de análise de cafeína em sementes de guaraná (Paullinia cupana). Revista Brasileira de Farmácia, Rio de Janeiro, v. 80, n.1-2, p. 7-9, 1999.

ANIRUDHAN, T. S.; RAMACHANDRAN, M. Adsorptive removal of tannin from aqueous solutions by cationic surfactant-modified bentonite clay. Journal of Colloid and Interface Science, Amsterdan, v. 299, n. 1, p. 116-124, 2006. http://dx.doi. org/10.1016/j.jcis.2006.01.056

ANIRUDHAN, T. S.; SUCHITHRA, P. S. Adsorptive characteristics of tannin removal from aqueous solutions and coir industry effluents using calcined and uncalcined hydrotalcites. Industrial \& Engineering Chemistry Research, Washington, v. 46, n. 13, p. 4606-4613, 2007. http://dx.doi.org/10.1021/ie061519s

ASSOCIAÇÃO BRASILEIRA DAS INDÚSTRIAS DE REFRIGERANTES E BEBIDAS NÃO-ALCOÓLICAS - ABIR. Disponível em: <http://www.abir.org.br/rubrique.php3?id_ rubrique=292>. Acesso em: 22 fev. 2009.

BABU, K. M.; CHURCH, R. J.; LEWANDER, W. Energy Drinks: The New Eye-Opener For Adolescents. Clinical Pediatric Emergency Medicine, Oxford, v. 9, p. 35-42, 2008. http://dx.doi. org/10.1016/j.cpem.2007.12.002

BRASIL. Presidência da República. Casa Civil. Subchefia para Assuntos Jurídicos. Decreto n 6871, de 4 de junho de 2009. Regulamenta a Lei no 8.918, de 14 de julho de 1994, que dispõe sobre a padronização, a classificação, o registro, a inspeção, a produção e a fiscalização de bebidas. Diário Oficial da República Federativa do Brasil, Brasília, DF, 04 jun. 2009. Disponível em: <https://www.planalto.gov.br/ccivil_03/_Ato20072010/2009/Decreto/D6871.htm>. Acesso em: 18 jan. 2012.

CALADO, V.; MONTGOMERY, D. C. Planejamento de Experimentos usando o Statistica. Rio de Janeiro: E-papers Serviços Editoriais, 2003. 260 p.

CARLSON, M.; THOMPSON, R. D. Liquid chromatographic determination of methylxanthines and catechins in herbal preparations containing guaraná. Journal of AOAC International, Gaithersburg, v. 81, n. 4, p. 691-701, 1998.

EDWARDS, H. G. M.; FARWELL, D. W.; OLIVEIRA, L. F. C.; ALIA, J. M.; LE HYARIC, M.; AMEIDA, M. V. FT-Raman spectroscopic studies of guarana and some extracts. Analytica Chimica Acta, Amsterdan, v. 532, p. 177-186, 2005. http://dx.doi.org/10.1016/j. aca.2004.10.055

ESPARZA, I.; SALINAS, I.; SANTAMARIA, C.; GARCIAMINA, J. M.; FERNANDEZ, J. M. Electrochemical and theoretical complexation studies for $\mathrm{Zn}$ and $\mathrm{Cu}$ with individual polyphenols. Analytica Chimica Acta, Amsterdan, v. 543, n. 1-2, p. 267-274, 2005. http://dx.doi.org/10.1016/j.aca.2005.04.029

HANLIN, R. L.; HRMOVA, M.; HARBERTSON, J. F.; DOWNEY, M. $O$. Review: Condensed tannin and grape cell wall interactions and their impact on tannin extractability into wine. Australian Journal of Grape and Wine Research, Adelaide, v. 16, n. 1, p. 173-188, 2010. http://dx.doi.org/10.1111/j.17550238.2009.00068.x

HEARD, C. M.; JOHNSON, S.; MOSS, G.; THOMAS, C. $P$. In vitro transdermal delivery of caffeine, theobromine, theophylline and catechin from extract of Guarana, Paullinia cupana. International Journal of Pharmaceutics, Amsterdan, v. 317 , n. 1, p. 26-31, 2006. http://dx.doi.org/10.1016/j. ijpharm.2006.02.042

HENMAN, A. R. Guaraná (Paullinia cupana var. sorbilis): Ecological and social perspectives on an economic plant of the Central Amazon basin. Journal of Ethnopharmacology, Maryland Heights, v. 6, n. 3, p. 311-338, 1982. http://dx.doi. org/10.1016/0378-8741(82)90054-X

HORWITZ, W. (Ed.). Official Methods of Analysis of the Association of Official Analytical Chemists. 16th ed. Gaithersburg: AOAC, 1996. 1298 p.

HUANG, J.; LIU, Y.; WANG, X. Selective adsorption of tannin from flavonoids by organically modified attapulgite clay. Journal of Hazardous Materials, Amsterdam, v. 160, n. 2-3, p. 382-387, 2008. http://dx.doi.org/10.1016/j. jhazmat.2008.03.008

HULBERT, G. J.; BISWAL, R. N.; MEHR, C. B.; WALKER, T. H.; COLLINS, J. L. Solid/liquid extraction of caffeine from guarana with methylene chloride. Food Science and Technology International, London, v. 4, n. 1, p. 53-58, 1998. http://dx.doi. org/10.1177/108201329800400107

KAWAMOTO, H.; NAKATSUBO, F.; MURAKAMI, K. Stoichiometric studies of tannin-protein co-precipitation. Phytochemistry, Oxford, v. 41, n. 5, p. 1427-1431, 1996. http://dx.doi. org/10.1016/0031-9422(95)00728-8

MAGALHÃES, P. J.; VIEIRA, J. S.; GONÇALVES, L. M.; PACHECO, J. G.; GUIDO, L. F.; BARROS, A. A. Isolation of phenolic compounds from hop extracts using polyvinylpolypyrrolidone: Characterization by high-performance liquid chromatographydiode array detection-electrospray tandem mass spectrometry. Journal of Chromatography A, Amsterdan, v. 1217, n. 19, p. 3258-3268, 2010. http://dx.doi.org/10.1016/j. chroma.2009.10.068

MAGNA, A.; SALOMÃO, A. A.; VILA, M. M. D. C.; TUBINO, M. Comparative Study of Two Spectrophotometric Reagents for Catechol Analysis in Guarana Seeds Powder. Journal of the Brazilian Chemical Society, São Paulo, v.14, n. 1, p. 129-132, 2003. http://dx.doi.org/10.1590/S010350532003000100021

MAKKAR, H. P. S.; BLÜMMEL, M.; BECKER, K. Formation of complexes between polyvinyl pyrrolidones or polyethylene glycols and tannins, and their implication in gas production and true digestibility in in vitro techniques. British Journal of 
Obtenção de extratos de guaraná ricos em cafeína por processo enzimático e adsorção de taninos RIBEIRO, B. D. et al.

Nutrition, Cambridge, v. 73, n. 6, p. 897-913, 1995. http://dx.doi. org/10.1079/BJN19950095

MEHR, C. B.; BISWAL, R. N.; COLLINS, J. L.; COCHRAN, H. $D$. Supercritical carbon dioxide extraction of caffeine from Guarana. Journal of Supercritical Fluids, Maryland Heights, v. 9, n. 3, p. 185-191, 1996. http://dx.doi.org/10.1016/S08968446(96)90031-5

MIE KARIYOU CORPORATION. Manufacture of guarana extract, useful as nutritive food or preventing and treating hepatic carcinoma, arteriosclerosis or aging, comprises treating powdered guarana fruits with carbohydrate degrading enzyme. P 2000-289739, 25 set. 2000.

PAGLIARUSSI, R. S.; BASTOS, J. K.; FREITAS, L. A. P. Fluid Bed Drying of Guarana (Paullinia cupana HBK) Extract: Effect of Process Factors on Caffeine Content. AAPS PharmSciTech, New York, v. 7, n. 2, p. E160-E166, Article 54, 2006. http://dx.doi. org/10.1208/pt070254

RODRIGUES, M. I.; IEMMA, A. F. Planejamento de Experimentos e Otimização de Processos. Campinas: Casa do Pão Editora, 2005326 p.

SALDAÑA, M. D. A.; ZETZL, C.; MOHAMED, R. S.; BRUNNER, $G$. Decaffeination of guarana seeds in a microextraction column using water-saturated $\mathrm{CO}_{2}$. Journal of Supercritical Fluids, Maryland Heights, v. 22, n. 2, p. 119-127, 2002. http://dx.doi. org/10.1016/S0896-8446(01)00121-8
SANTOS-BUELGA, C.; SCALBERT, A. Proanthocyanidins and tannin-like compounds - nature, occurrence, dietary intake and effects on nutrition and health. Journal of the Science of Food and Agriculture, Londres, v. 80, n. 7, p. 1094-1117, 2000. http:// dx. doi.org/10.1002/(SICI)1097-0010(20000515)80:7<1094::AIDJSFA569>3.0.CO;2-1

SIMÕES, C. L. O.; SCHENKEL, E. P.; GOSMANN, G.; MELLO, J. C. P.; MENTZ, L. A.; PETROVICK, P. R. Farmacognosia: da Planta ao Medicamento. 5. ed. Porto Alegre: Editora UFRGS; Florianópolis: UFSC, 2003. 821 p.

SOMOGYI, M. Notes on Sugar Determination. The Journal of Biological Chemistry, Maryland, v. 195, p. 19-23, 1952.

SPENCER, C. M.; CAI, Y.; MARTIN, R.; GAFFNEY, S. H.; GOULDING, P. N.; MAGNOLATO, D.; LILLEY, T. H.; HASLAM, E. Polyphenol Complexation - Some thoughts and observations. Phytochemistry, Oxford, v. 27, n. 8, p. 2397-2409, 1988. http:// dx.doi.org/10.1016/0031-9422(88)87004-3

WATERMAN, P. G.; MOLE, S. Analysis of Phenolic Plant Metabolites. Oxford: Blackwell Scientific Publications. 1994. 248 p.

WU, Y.; CHEN, Z.; LI, X.; LI, M. Effect of tea polyphenols on the retrogradation of rice starch. Food Research International, Ottawa, v. 42, n. 2, p. 221-225, 2009. http://dx.doi.org/10.1016/j. foodres.2008.11.001 